\title{
InDret
}

\section{Economics and Evolutionary Psychology}

\section{David D. Friedman}

Barcelona, April 2001

www.indret.com 


\section{Summary}

- Evolutionary Psychology: The Short Version

- What Evolutionary Psychology Adds

- Economic Puzzles and Just Prices

- Evolutionary Psychology and the Just Price

- A Bird in the Hand: Evolutionary Psychology and Preferences Over Time

- Conclusion 
Economics is built on one simple assumption-that individual behavior can best be predicted by assuming that each individual will take the actions that best achieve his objectives. The reason for that assumption, usually and somewhat misleading labelled "rationality," is that although individuals are in part irrational we have no good theory of mistakes, no way of predicting what particular irrational action they will take, hence it is the rational element in behavior that can be used to predict it. ${ }^{1}$

Evolutionary psychology offers a challenge to the rationality assumption, since it provides us with a theory of mistakes. In this essay I sketch out the nature of that theory, describe some puzzles that economics has a difficult time explaining, and try to show how modifying economics with the aid of evolutionary psychology might help explain them.

\section{- Evolutionary Psychology: The Short Version}

Evolutionary psychology2 starts from two simple assumptions:

1. The human mind is best understood not as a general purpose computer but as a set of specialized software modules, each designed to deal with a particular subset of problems.

2. Those programs have been designed, by Darwinian evolution, to produce reproductive success in the hunter-gatherer environment in which our species spent most of its species history.

Researchers in evolutionary psychology, starting with these assumptions, have generated and tested predictions ranging from differences in male and female abilities to the timing of morning sickness.

Three important points are worth making about the second assumption, in order to avoid misunderstanding. The first is that the assumption is not that individuals seek reproductive success-if we did that, the population of developed countries would be increasing much faster than it is-but only that we have those psychological characteristics that produced reproductive success in the environment we evolved in. The second is that reproductive success is an objective for the individual, not the group or species. Most scholars in evolutionary biology accept the view that traits which

1 The argument is summarized in D. Friedman, Hidden Order: The Economics of Everyday Life, HarperCollins: N ew York 1996, pp. 3-9. A webbed version, from D. Friedman, Price Theory, can be found

http:/ / www.daviddfriedman.com/ Academic/ Price Theory/ PThy_Chapter 1/ PThy CHAP 1. html

2 For a good description and defense of evolutionary psychology, along with a number of interesting applications, see The Adapted M ind. Evolutionary Psychology and the Generation of Culture, by John Toobey, Leda Cosmides and Jerome H. Barkow, Oxford University Press: New York, 1995. 
benefit group or species at the cost of the individual who carries them will be selected out. $^{3}$

The third point is that we are adapted, not to the world we now live in, but to the environment in which our species spent most of its history. Agriculture is, from an evolutionary perspective, a fairly recent development. Hence we would expect that most of our characteristics would be designed to produce reproductive success in the environment that preceded agriculture-believed to be an environment of small hunter gatherer bands.

\section{- What Evolutionary Psychology Adds}

Evolutionary psychology implies two modifications to the rationality assumption. The first is an increase in its precision. Economists assume that individuals have objectives, but economic theory does not tell us what those objectives are, although real world economists do have at least some idea, based on observation and introspection, of what they are likely to be. Evolutionary biologists, on the other hand, know what the objective of genes ${ }^{4}$ is-reproductive success, getting as many copies of themselves as possible into future generations.

Hence adopting the assumptions of evolutionary psychology gives economists some ability to predict what utility functions individuals will have. That ability is limited by our ignorance of the opportunity sets facing the genes-what sorts of organisms it is possible for them to construct. Pretty clearly, if there were a way of constructing a (phyloprogenitive) superman, a human being much stronger, faster, healthier, smarter, than existing humans and capable of surviving on practically anything, the gene that pulled off the trick would be a big winner in the Darwinian race. The absence of such supermen suggests that it cannot be done, or at least that doing it is so difficult that no gene has yet had managed it.

A less obvious example of the same point is the observed limit in just how phyloprogenitive real human beings are. We are designed to seek reproductive success through a variety of traits-desire for sex that leads us to reproduce, parental love that leads us to care for our offspring, and many others. But despite those traits human beings, in the environments of recent centuries, reproduce at far less than the individual biological maximum-in part because we have found ways, ranging from birth control

\footnotetext{
2 It is logically possible for traits that benefit a group at the expense of the group members who carry them produce an increase in success for the group large enough to make up for the decreased success of the member relative to other members of the group, but that is usually viewed as an unusual special case.

4 "Objective of genes" is, of course, a metaphor. Genes do not have minds, hence do not have objectives. But the organisms we observe are constructed by those genes that succeeded, in past generations, in constructing organisms that got those genes passed down. Hence genes are shaped, as by an invisible hand, to construct organisms whose characteristics result in reproductive success for the genes that constructed them.
} 
to pets, to sabotage the objectives of our genes in order to better serve our own objectives. ${ }^{5}$ A true phyloprogenitive gene, one that made reproductive success the highest priority of every individual, would confer an enormous reproductive advantage on its carriers and rapidly spread through the population. ${ }^{6}$ The absence of such a gene is presumably due to the difficulty of such precise programming of an organism as complicated as a human being, plus the short time that has passed since the developments that make that tactic for reproductive success so much superior to less direct approaches.

Knowing the objective of our genes is not sufficient to tell us, with confidence, the objectives of the human beings that those genes build. But it is enough to suggest hypotheses-characteristics that would lead to increased reproductive success and that it might be possible for genes to give to the organisms they construct. Having formed such hypotheses, we can then test them by comparing their predictions to what we observe.

What I have described is the methodology routinely used in evolutionary biologyincluding, but not limited to, evolutionary psychology. It is the same as the methodology of positive economics save for a different and more explicit procedure for forming hypotheses.

One way in which evolutionary psychology modifies the rationality assumption is by predicting what objectives individuals are likely to have. A second is by providing a theory of mistakes.

Compared to rational thinking, Darwinian evolution is a slow process. Hence while we expect the rational individual assumed by economists to choose the actions that achieve his objectives in the environment he observes around him, we expect the individual produced by evolution to be designed to achieve his objectives-more precisely, his genes' objectives-in the environment in which his species evolved. It follows that individuals will be irrational-will be designed to act in ways not well designed to achieve their objectives-when the relevant features of the environment have changed rapidly enough so that evolution has not yet had time to catch up. Thus the theory predicts not merely that individuals will make mistakes-that we already knew-but what mistakes they will make. They will make those mistakes that would have led to reproductive success in the environment in which the psychological characteristics leading to those mistakes evolved.

\footnotetext{
${ }^{5}$ Reference Dawkins revolting robots.

${ }^{6}$ In developed societies most couples have about two children but could easily produce and rear eight-if doing so were their highest priority. A gene that resulted in their doing so would increase its frequency in the population a billion fold in a mere fifteen generations.
} 


\section{- Economic Puzzles and Just Prices}

There are a variety of economic puzzles-patterns of consistent behavior that appear difficult, if not impossible, to explain by the usual economic approach. In this section I will describe several of them, argue that they can all be reduced to a single characteristic of human psychology, and attempt to show that it is likely that that characteristic, while it makes its possessor worse off in many (but not all) of the situations to which it applies in modern society, made its possessors better off in the hunter-gatherer environment in which, according to evolutionary psychology, our psychology evolved.

The first puzzle is the existence of predictable lines. Consider a restaurant whose patrons know that if they come for dinner on Friday or Saturday they will have to wait forty-five minutes for a table. The line does not increase the number of people the restaurant can serve, 7 but it does impose an additional cost on customers in waiting time, thus raising the total cost of the meal enough to reduce quantity of meals demanded to the quantity the restaurant is capable of producing.

Suppose the wait is the equivalent, from the standpoint of the patrons, 8 to a ten dollar increase in price. If the restaurant simply raised its price for the nights it was busy by ten dollars, the line would shrink to close to zero, the patrons would be no worse off-they would be paying the extra price in money instead of time-and the restaurant would be better off by ten dollars per diner. In the longer run, the increase in the amount restaurants could charge on busy nights would increase the supply of restaurants, bringing down the price and transferring at least some of the benefit back to the patrons.

Restaurants do, to some extent, vary their price in this way-usually by announcing special discounts for low demand nights rather than special surcharges for high demand nights. ${ }^{9}$ Nonetheless, predictable long lines are a familiar feature of the restaurant world-which suggests that there is some significant constraint limiting the degree to which they can vary their prices. A similar pattern is observed in many other contextsconcerts, opening nights of popular films, and the like. Producers frequently follow pricing polices that lead to wasteful competition for under priced goods. Doing so appears to make the producer worse off, hence to be inconsistent with the assumption of rationality.

One response consistent with at least casual observation is that a rock group or movie theater that routinely charged a price sufficient to ration demand down to supply for high demand events would offend its customers and thus lose more in the long run than it gained in the short. But this explanation raises a second puzzle - the behavior of the customers. The average customer is no worse off in the short run as a result of such a

\footnotetext{
${ }^{7}$ A short line would increase the number served, since it provides an inventory of customers that allows the restaurant to produce a full capacity in the face of unpredictable demand. I am now considering the effect of the additional wait beyond that necessary to achieve that effect.

8 Patrons are not, of course, identical, but for my present purposes it is not necessary to discuss the differing effects on patrons with differing value for time.

9 This pattern fits the explanation I propose below.
} 
policy, since it merely converts cost in time into cost in cash. And he is better off in the long run. So why should customers be offended? More precisely, why should they choose not to patronize producers who price their goods in the way that economic theory suggests they should?

A second and less striking puzzle is why firms that sell the same product at different prices at different times almost invariably describe their policy in terms of a normal price and a discount rather than a normal price and a surcharge. This is less puzzling than the existence of predictable lines because there is no strong argument against doing it that way. But there is no strong argument for, either. Given that we already know what firms do, it is tempting to argue that doing it that way makes them look goodthey are giving their customers a special deal. But one could as easily argue that the alternative policy makes them look good because it implies a lower ordinary price.

Next, consider the history of price control. A law fixing a legal price below the price that would emerge from the market has a variety of consequences. In the long run, it is likely to make almost everyone worse off.10 In the short run, however, it may well benefit purchasers at the expense of producers-and for some products, most notably rental housing, the short run may be long enough to produce substantial transfers. Furthermore voters are, for familiar reasons, rationally ignorant, and long run costs are often less obvious than short run benefits. Hence it is not astonishing that price control is sometimes politically profitable.

What is surprising is the pattern of when it is politically profitable. The costs and benefits of holding a price ten percent bel ow its market level do not depend on whether the restriction prevents a price rise or forces a price reduction. ${ }^{11}$ But in practice, the former case is very much more common than the latter. Price control almost always arises in a context where it is intended to prevent prices from rising, very rarely in a context where a price is stable and the control is designed to push it below its current level.

All of these puzzles can be explained by a single assumption: That individuals believe there is a proper price for a good, that it is equal to the price at which they are used to buying the good, and that they resent being charged more than that price. That assumption is consistent both with casual observation of reactions to sharp price increases and with the history of ideas such as the scholastic philosophers' doctrine of the just price. ${ }^{12}$

10 For an analysis of the reasons this is true, see Price Theory. An Intermediate Text, $2^{\text {nd }}$. Ed., South Western Publishing Co.: Ohio 1990, pp. 482-485 and Hidden Order: E conomics of Everyday Life, op. Cit., pp. 245-251.

11 This is a slight oversimplification, since there are some costs associated with the mechanics of pricing, such as revising price tags and prices in advertisements, which are incurred if price control forces prices down but avoided if it prevents prices from going up.

12 For an discussion of that doctrine and the function it served, along lines related to the argument of this essay, see D. Friedman "In Defense of Thomas Aquinas and the Just Price." For some evidence of similar attitudes in modern consumers, see Richard $\mathrm{H}$. Thaler, Mental Accounting and Consumer Choice, M arketing Science, 1985. For a more extensive discussion of 
Seen from the standpoint of economic rationality, the assumption makes little sense. Most people have no clear idea of what determines the prices of the goods they buy. Hence they have no way of knowing whether yesterday's price was fair, or just, or cost justified, or whether today's higher price fails any of those criteria.13

If we consider the behavior associated with a belief in just prices, it too makes little sense. Suppose that I really do know that a particular price is in some meaningful sense "too high"-say that it is higher than the economically efficient price. Why is that a reason for me not to buy the good, assuming it is still worth more to me than it costs? Why is it a reason for me to be angry at the seller, and express that anger by avoiding future transactions with him, even if they would benefit me? In a world where goods and services are sold to large numbers of anonymous customers, I cannot reasonably expect my refusal to buy, however justified, to induce the seller to lower his price.

\section{- Evolutionary Psychology and the Just Price}

Let us now shift our analysis back twenty thousand years. You are a member of huntergatherer band. You engage in a variety of transactions with your fellow members, trading goods and, probably more important, services. While money has not yet been invented, prices-the goods you must give in exchange for goods, or the favors you must do someone if you want him to do a favor for you-are a familiar part of your environment. In this world, all markets are thin-it is, after all, a small band. It follows that the typical transaction is a bilaterial monopoly bargain.

Assume an environment sufficiently stable so that, for some transactions, there are "usual prices." Those prices must be within the bargaining ranges of both buyer and seller, ${ }^{14}$ since otherwise the transactions would not occur. The environment is not, however, perfectly stable. Sometimes the circumstances of one party or another shift his bargaining range - the range of terms that make the transaction in his interest.

Suppose I am a buyer, and my current circumstances make the good much more valuable to me than usual, widening the bargaining range. If I could somehow commit myself not to pay more than the usual price, that would guarantee that I, not the seller, will receive the increased gains to trade from this transaction. One way to do so is to be emotionally programmed to resent any increase above the usual price-resent it enough so that the humiliation of being "cheated" will outweigh the gain from the transaction.

modern behavior patterns inconsistent with the usual economic account of rationality, along with a good deal of evidence, see $Q$ uasi-R ational E conomics by Richard $H$. Thaler.

13 "For one thing, the recent tripling of oil prices followed a sharp drop. In real terms, prices are still one-third below their level in 1990, when Iraq invaded Kuwait, and half their level in 1981." The E conomist, Sept 9, 2000 p. 17,

14 Strictly speaking, the distinction is irrelevant here, since we are talking about barter transactions, but it is still useful for explanatory purposes. 
As in any bilateral monopoly game, the argument works both ways. If the seller could somehow commit himself not to accept less than your reservation price, ${ }^{15}$ he would be the one to pocket the gains from the trade. There is, however, an important difference between your situations. You know the usual price and, assuming the special circumstances affect only you, you know that it is probably within the seller's bargaining range. Hence your commitment strategy is unlikely to commit you to a price outside the bargaining range and thus make the transaction impossible. The seller does not know your reservation price, so if he commits himself to his guess at what you are willing to pay, he may choose a price at which the transaction will not occur.

A second difference is the fact that the usual price is common knowledge of both parties. Hence if the seller believes that the buyer is committed not to pay more than the usual price, he knows how much he can ask. But if the buyer believes that the seller is committed not to accept less than the buyer's reservation price, he still has to guess what the seller believes that is.

The strategy works symmetrically when the seller is, for special reasons, willing to accept a much lower price than usual - on a barter market, these are really two different descriptions of the same situation. And, returning briefly to the present, we observe that people resent not only unusually high prices when they are buyers but unusually low prices when they are sellers-giving us, among other things, one explanation for why wages are sticky downwards.

What about the situation where the seller's costs are unusually high, making him unwilling to sell at the usual price? If the result is to eliminate the bargaining range, no transaction will, or should, take place. But if the seller's cost is lower than the value to the buyer, either because the special circumstances affect both in similar ways or because the increased cost is still within the usual bargaining range, a buyer's commitment not to pay more than the usual price results in an inefficient bargaining breakdown.

There is a solution to this problem, however, and one observed in the real world. A seller charging an unusually high price can defend himself against the buyer's commitment strategy by offering to show the buyer that his costs really are unusually high, hence that he is really, and not only strategically, unwilling to sell at the usual price. Hence we get the conventional view of pricing that economists find so frustrating and wrongheaded-as the outcome of bargaining between buyer and seller, with each required to "justify" any deviation from the usual price in his favor.

It follows that, in the context of a hunter gatherer society (more generally, a society where most transactions take place on thin markets) belief in a just price-defined as the usual price - can be understood as a commitment strategy that benefits those who adopt it. The benefit depends on an environment sufficiently stable so that knowledge of past prices provides a simple rule for identifying a price that is probably within the other

15 More realistically, to insist on a price a little below your reservation price, so as to reduce risks from error. The distinction is not important to my general argument, so I will ignore it below in order to simplify the discussion. 
party's bargaining range. It works better the better bargainers can identify the cases where the rule does not work-where it results in one party demanding a price outside of the bargaining range.

We now have a possible solution to the set of puzzles described above. Human beings have a functional module in their minds that deals with exchanges with other human beings. One feature of that module, hard wired in by evolution, is that human beings regard the usual terms of exchange as right and any deviation from those terms that makes them worse off as presumptively a wicked act by the other party. This feature resulted in human beings that possessed it getting, on average, better terms in bilateral monopoly bargains in the environment in which we evolved, hence in their having more resources and so achieving greater reproductive success, hence in the genes responsible for that feature spreading through the population.

This feature continues to benefit those who hold it under some circumstances-markets with the features I have described. They injure those who hold it in the anonymous mass market settings in which most modern economic transactions occur. And the fact that other people have that characteristic makes me worse off, both because it leads to inefficient policies by firms (lines) and governments (price control), and because it leads to those others getting better terms from me when we happen to be in a bilateral monopoly transaction.

\section{- A Bird in the Hand: Evolutionary Psychology and Preferences 0 ver Time}

Intertemporal choice provides a second example of puzzling behavior that may perhaps be explained by evolutionary psychology. The usual economic model, going back at least to Marshall16 and given its present form by Samuelson, 17 assumes that an individual's preferences between present and future utility can be described by a discount rate. The preferred alternative is then the one that maximizes the present value of utility, discounted at that rate. Mathematically:

$U=U_{1}+U_{2} /(1+r)+U_{3} /(1+r)^{2}+\ldots$

Where $r$ is the individual discount rate on utility, $U$ is the utility that the individual maximizes, $U_{1}$ is the utility received in year $1, U_{2}$ in year 2 , and so forth.

While it is not clear that this particular structure is required by rationality, it does have some attractive properties. In particular, it guarantees that the preference between two future alternatives at different dates does not change as we approach them; individual choice is, in that sense, consistent over time.

\footnotetext{
${ }^{16}$ Alfred Marshall, Principles of E conomics, Bk III chapter $\bigvee \S 3,4$.

17 Samuelson, Paul, "A N ote on Measurement of Utility," Review of Economic Studies 4, (1937): pp. 155-161.
} 
While this seems a plausible description of rational choice, it does not appear to describe real world behavior very accurately. ${ }^{18}$ A variety of experiments show that many individuals, faced with (say) the choice between a thousand dollars today or eleven hundred dollars next week, will prefer the former, yet faced with the choice between a thousand dollars a year from now and eleven hundred dollars a year plus a week from now, will prefer the latter. The usual pattern appears to be a very high discount rate for choices in the near future and an increasingly low discount rate as the alternatives become more distant. 19

Evolutionary psychology suggests a straightforward explanation for such a pattern. In the experimental setting, subjects are told that they are choosing between two certain payoffs at different times. In the world in which we now live, that is a believable story; modern financial institutions make possible very secure promises of future performance, such as those embodied in certificates of deposit or U.S. government bonds.

But the world in which our species evolved did not have such institutions. In that world it was rational to heavily discount promises of future performance. One deerskin today was worth a great deal more than one deerskin next week because today's deerskin was there to be taken; next week's might not be. One deerskin a year from now, on the other hand, was not worth much more than one deerskin a year plus a week from now; both were promises that might well fall through, and the chance of their falling through was not greatly altered by the additional week.20

18 For an extensive discussion of the experimental evidence and various attempts to interpret it, see George Loewenstein and Jon Elster, Choice O ver Time, Russel Sage Foundation, N.Y. 1992.

19 The observed pattern is sometimes described as "hyperbolic discounting," since it fits a hyperbolic function better than it fits the exponential implied by the conventional economic model of intertemporal choice.

20 This would not be true if we modeled contract non-fulfillment as the result of a stochastic process where each week there was a certain probability that the other party would decide to renege on his obligation. That would yield the same result-expected vale declining exponentially with time-as the conventional model.

But there are at least two more plausible models that work better:

1. Fulfillment depends on the relations between the two parties at the time the obligation comes due. Relations each week have some probability of switching from friendly to unfriendly, and also some probability of switching from unfriendly back to friendly. They are friendly when the agreement is made. As time goes on, the expected state of relations moves towards its equilibrium level.

2. Fulfillment depends not on future events but on the present plans of the other party. The longer it is until the obligation comes due, the easier it is for him to get out of it-to be somewhere else, or to have acquired allies to use against any retaliation by your for nonperformance, or to claim to have forgotten it (this is, after all, a world without writing). Hence the fact that the offer is well into the future signals that he does not intend to fulfill it. 
Not only was the behavior rational twenty thousand years ago, it was, to a considerable degree, rational a good deal more recently, sufficiently so to become proverbial. "A bird in the hand is worth two in the bush."

\section{- Conclusion}

I have offered two examples of patterns of behavior apparently inconsistent with the usual account of economic rationality that may be explained, arguably even predicted, by evolutionary psychology. Behavior associated with deeply held beliefs about just prices makes sense as a hardwired commitment strategy, designed to give its holder an advantage in the bilateral monopoly bargains that must have been common in the hunter gatherer societies in which our species evolved. A pattern of apparently inconsistent choices over time makes sense as reflecting the lack of reliable mechanisms for guaranteeing the performance of future obligations in that same society.

In both cases, evolutionary psychology plays the second of the two roles that I described at the beginning of this article-it functions as a theory of mistakes. That is not surprising. Insofar as evolutionary psychology tells us what our utility function is, it improves upon the economic model of rationality but does not contradict it. It is only when it tells us what actions we will take that do not serve our interests that it contradicts the conventional approach, and so makes it possible to find evidence for one and against the other.

This article is a first pass at a large problem. I hope others will find it sufficiently interesting to want to both extend the analysis to other economic puzzles and sharpen the tests it generates so as to provide something more like evidence and less like anecdote to help us choose between the alternative approaches to human behavior offered by economics and evolutionary psychology. 